\title{
SURVEY OF THE PAGODA TIMBER ROOF IN DERNEBURG CASTLE
}

\author{
E. Perria ${ }^{a}$, M. Sieder ${ }^{\text {b }}$, S. Hoyer ${ }^{\text {c }}$, C. Krafczyk ${ }^{d}$ \\ ${ }^{a}$ iBHolz, Institut für Baukonstruktion und Holzbau, Technische Universität Braunschweig, Schleinitzstraße 21A \\ 38106 Braunschweig - e.perria@tu-braunschweig.de \\ b iBHolz, Institut für Baukonstruktion und Holzbau, Technische Universität Braunschweig, Schleinitzstraße 21A \\ 38106 Braunschweig - m.sieder@tu-braunschweig.de \\ ${ }^{\mathrm{c}}$ Institut für Tragwerksentwurf, Technische Universität Braunschweig Pockelsstrasse 4, \\ 38106 Braunschweig - s.hoyer@tu-braunschweig.de \\ ${ }^{\mathrm{d}}$ Institut Bauwerkserhaltung und Tragwerk, Technische Universität Braunschweig, Beethovenstr. 51 \\ 38106 Braunschweig - c.krafczyk@tu-braunschweig.de
}

KEY WORDS: Timber structures, Structural analysis, Roof, CAD representation, Laser scanner survey.

\begin{abstract}
:
The work analyses the historical roof of Derneburg Castle, in the municipality of Holle, Hildesheim's district, Lower Saxony, Germany. The roof is assembled according to Laves Balken's system (Laves beam's system), developed by the architect Georg Ludwig Friedrich Laves $(1788$ - 1864). The system has the peculiarity to consist of beams that are split along the half of the cross section, and maintained diverged by wooden wedges, distributed along the length of the beam. The system increases the height of the beam, and elevates the bending capacity of it (Weber, 1964). The work has been developed in the frame of an interdisciplinary project in the fields of architecture, engineering and photogrammetry. Main aim of the project is the developing of a structural model to understand the load-carrying capacity of Laves Balken's system from the laser-scanning model. For this reason, extensive surveys and photo documentation were collected on three areas of the roof construction, characterized by three peculiar usage of Laves Balken's system. The work presents the survey of the pagoda-roof that covers the tower of the castle, and problems that can be encountered during the survey of very complex timber constructions.
\end{abstract}

\section{INTRODUCTION}

The documentation and the structural analysis are two crucial points to the assessment and the preservation of built heritage. Although, it can be easily observed that architectural representation and engineer structural analysis have been divided by different needs that computer techniques have not yet been jointed together.

Thanks to 3D data virtual models, textured surfaces and videos, architectural representation has been significantly improving the way of describing, visualization, documenting edifices, historical buildings, and sites. Nevertheless, the focus of the architectural survey is graphics and illustrations connected with realism.

Despite the surveyed object can be easily accessible up to millimetric details, when the documentation and the representation media would be integrated with the engineered structural analysis, is faced a lack of appropriate information in the survey.

Furthermore, the efforts that are connected with the modelling of the CAD model for the representation and framework model for the structural analysis add together because not compatible.

In light of this notion, this paper describes the documentation of a significant cultural heritage monument, the historical wooden pagoda roof in Derneburg Castle. The survey was performed with Terrestrial Laser Scanning (TLS) techniques. The paper illustrates all the problems that were encountered during the surveying and the post-processing with the aim of CAD representation and structural analysis of the object.

\section{THE PAGODA OF DERNEBURG CASTLE}

\subsection{Historical background}

Derneburg castle was built on the ruins of a former monastery by will of the Count of Münster in the year 1815. The manor house was many times re-modelled by the Münster family since it was sold in the 1975. Since 1995, the Baselitz family modified the property into an extensive atelier, including the castle park that was spread with paintings and sculptures.

The castle is characterized by a U-shaped plan consisting of three wings, a main one, and two side wings arranged east and west. At the end of the western wing is situated the tower covered by a pagoda-shaped roof construction (Figure 1), that is the landmark of Derneburg town (Gemeinde Holle (b)).

\subsection{The Laves Balkens' technique}

The roof is assembled according to Laves Balken's system (Laves beam's system), developed by the architect Georg Ludwig Friedrich Laves (1788 - 1864). The peculiar system consists of beams that are split along the half of the cross section, and maintained diverged by wooden wedges, distributed along the length of the beam. The system increases the height of the beam, and elevates the bending capacity of it (Weber, 1964). The pagoda rood constitute a spectacular example of use of the Laves Balken's technique (Figure 2). The load-carrying elements are built according to Laves Balken's principle, but they are composed by two independent beams held together by bolts and wooden strips at the extremities, and maintained apart in the central part of the beams by wedges and intermediate purlins. 


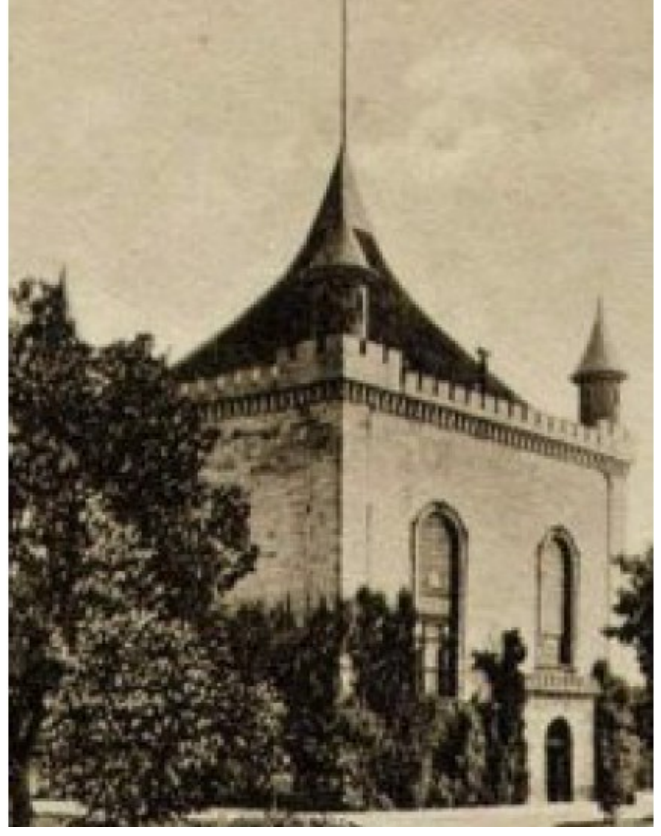

Figure 1. Tower covered by the pagoda-roof and adorned with battlements depicting the reconstruction after the year 1848 (Gemeinde Holle (a))

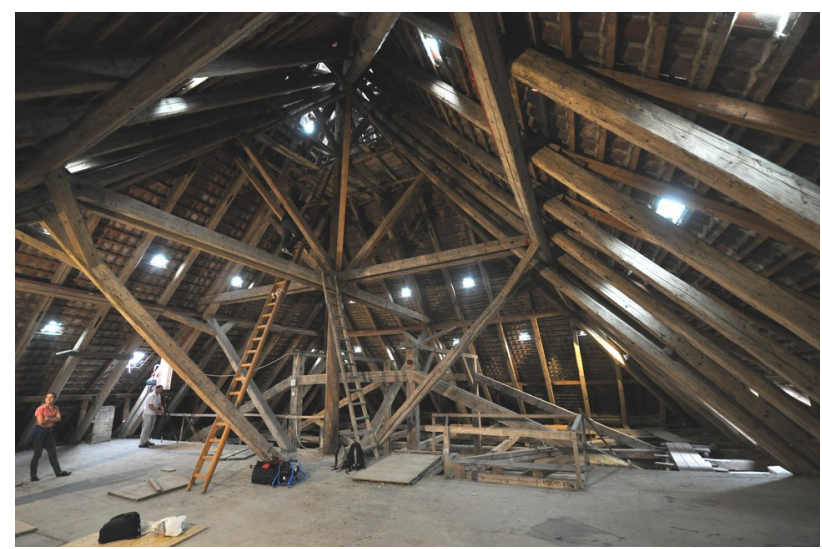

Figure 2. The pagoda-shaped timber structure during the operations of survey.

\section{SURVEY OF THE STRUCTURE}

The aim of the survey is the representation of the complexity of the structure and his joints, targeted to the structural analysis of the roof. The criteria used in the assessment of traditional timber buildings includes (Cruz, 2013) a measured survey to determine the overall disposition of the structural members and locate the main problems. This survey [...] should include principal dimensions and the nominal sizes of all members. It should also note any obvious signs of damage, decay, or structural distress, which will need to be investigated in more detail at a subsequent stage.

For the acquisition of the data on the pagoda-roof, two different instruments and methods were applied: Leica 3D Disto and Leica ScanStation P20 technologies. In fact, during the performing of the surveys, some procedural issues arose, and time to time, some considerations had to be done.

\subsection{Leica 3D Disto}

A first survey was done using Leica 3D Disto with a control unit tablet.

The equipment was used first with the option to scan objects automatically along a given plane. With the aim of structural analysis, the information on beams' lower sides with irregular cross sections and finishing is not relevant. The obtained image were incomplete; therefore, the automation of the survey was not considered as a possible option.

As second step, a manual procedure was performed. Here, the points to survey were manually selected by the operator. It was chosen to obtain information about the middle points of the trusses, in order to build the main members' axis. The acquisition of the points was possible thanks to the camera and the pointer laser installed in the equipment that let the visual acquisition of the data on the Leica software on a tablet.

The visual survey increased the amount of data on the structure, and the drawing of some of the main load-bearing elements was possible; nevertheless, the complexity of the timber roof, the height of the structure and the lack of visibility for the positioning of the target-laser were an obstacle to the correct survey of the structure. Furthermore, the presence of disturbing elements like non load-bearing beams, inspection platforms, and the deformed status of the structure (irregular cross sections, structural imperfections and element's deflections) made the survey incomplete, and with lack of sufficient pieces of information for the representation and the analysis.

\subsection{Leica ScanStation P20}

One of the main purposes for adopting the 3D laser technology is the advantage to record large amount of high-resolution information in order to model very articulated and complex timber structures, also under unfavorable visibility conditions (Balletti, 2014 \& Bertolini-Cestari, 2016). Therefore, a second survey of the pagoda-roof was performed with a Leica ScanStation P20. The obtained clouds have been post-processed using the Cyclone software.

Nevertheless, some other factors influenced the easy acquisition of the data. First, because of a difference of height between the left and the right side, not the whole ground level was available for the placement of the stations. Second, due to the presence to inspection platforms at a higher level, the visual accessibility of the pagoda's peak was possible only from one side. Therefore, the point cloud was acquired thanks to the positioning of three stations on the half of the ground level of the attic that permitted the achievement of necessary pieces of information about all main structural elements up to the pagoda's top. The position of the stations was chosen in order to optimize the complete data recording of the complex structure; nevertheless, the non-structural elements that crowd the roof, create difficulties not only during the survey, but also in the postprocessing of the data. Once more, these elements:

1. create noise;

2. conceal the complete information on structural elements;

3. cause non-necessary increase of cloud's number of points;

4. make the post-representation of the structure laborious, due to the manual selection of elements. 


\section{POST-PROCESSING OF THE SCANNING DATA}

The data were post processed with the use of two main programs. The extrapolation of pieces of information about the dimension of the structural elements was done with Autodesk ReCap, while the modelling of the structure was done with CADwork wood. The modelling with the final aim of the structural analysis needs of further time to be performed. Therefore, the description of the post-processing is here limited to the CAD modelling, and some aspects of the preparation of the framework model for structural analysis are commented in the section 5 .

\subsection{Post-processing with ReCap}

Autodesk ReCap converts raw scan data to scan files (RCS files), and project files (RCP files) that reference multiple RCS files. The large collection of points acquired by laser scanner is visualized into the program as threedimensional image (Figure 3).

The automatic meshing of the roof elements represented in the point cloud was not possible because of the noise of nonstructural elements, and the irregularity of the structural elements (in fact, the program can only recognize planes and cylinders). Therefore, thanks to the box tool, the point cloud was sliced into sections, that are exported as images, and attached to the CAD drawing, using them as a guideline for the next step of the modelling. The most of the data that were extrapolated from the point cloud are about the main sections (Figure 5 and Figure 6). Some details (Figure 4) were also visualized and measured with the measuring tool.

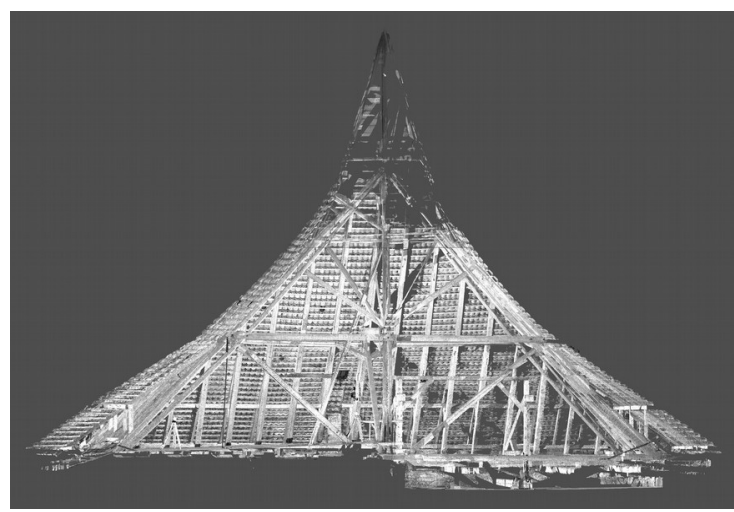

Figure 3. Section of the pagoda roof that shows the inner part of the structure.

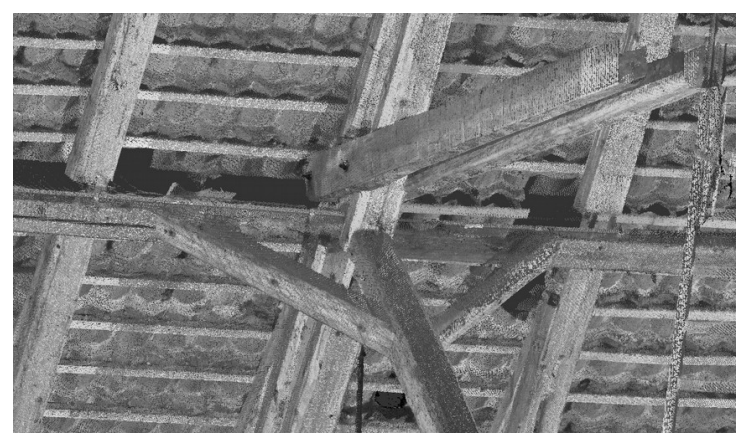

Figure 4. ReCap image of detail of the intermediate connection point among the Laves' beam, tie beams and the supporting element with inclined braces.

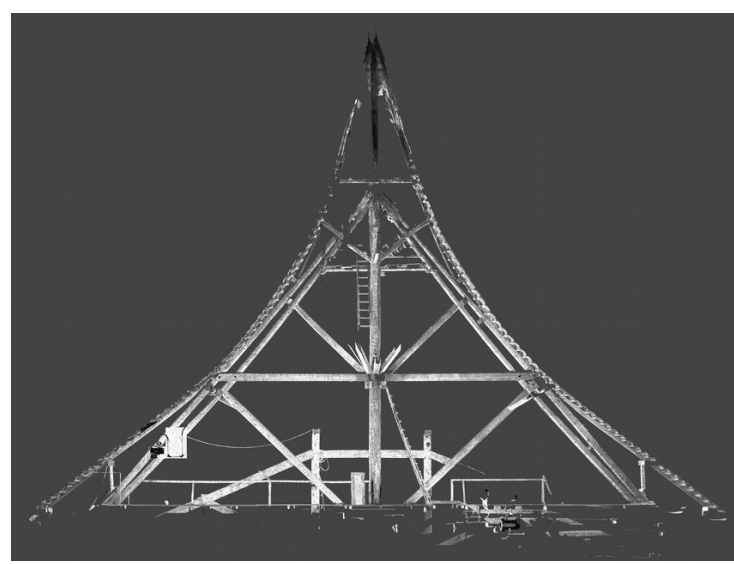

Figure 5. Longitudinal section of the pagoda. The main structural elements are extrapolated thanks to the box tool.

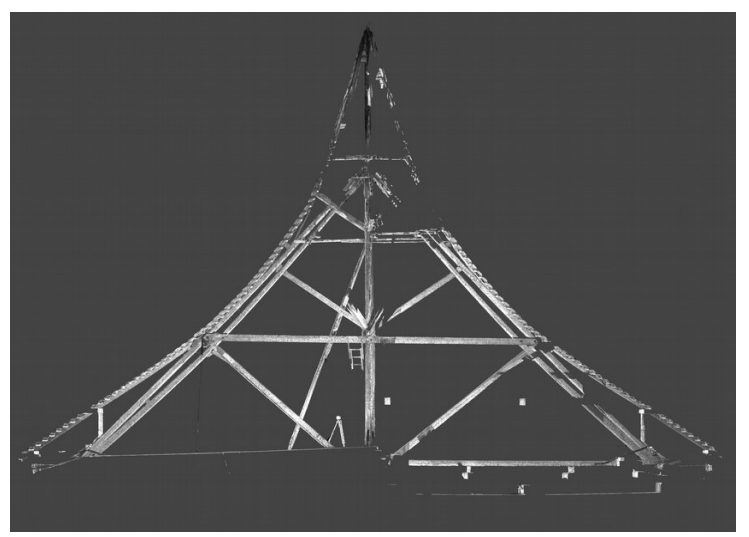

Figure 6. Transversal section of the pagoda. The main structural elements are extrapolated thanks to the box tool.

\subsection{Representation with CADwork wood}

The CADwork wood is a specific software for the CAD representation of timber frame and solid timber structures. The representation of the structural components can be automatically displayed as piece-by-piece drawings with dimensions and individually configured material, both in $2 \mathrm{D}$ and $3 \mathrm{D}$. The software is particularly useful for timber constructions, because every beam element can be jointed and individually exchanged, and with the possibility to use carpentry joints at the extremities of the beams.

The modelling of the pagoda was performed manually, from the sections' images as guidelines, and 'direct' measurements of structural elements visualized in $\mathrm{ReCab}$, thanks to the measuring tool. The result of CAD modelling is represented in Figure 7, and the transversal section in Figure 8.

However, it was not possible to model all the structural elements from sections or 'direct' measurements in the point cloud. In fact, some shade areas formed during the survey, rendering the point cloud incomplete. For what concern the drawings of some details, like the foot points of the Laves' beams and other sensitive points, the modelling of the structure did not follows only the point cloud, but the automatic scanning had to be integrated with the direct survey of the elements through photos (Figure 9) and hand-measured sketches 
(Figure 10). The detail in Figure 10 represents one example of this manual survey.

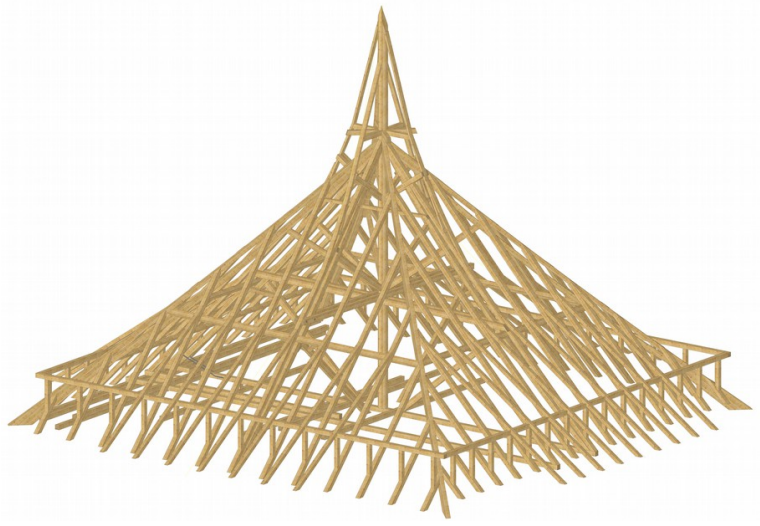

Figure 7. CAD view of the pagoda roof.

Figure 8. CAD transversal section of the pagoda.

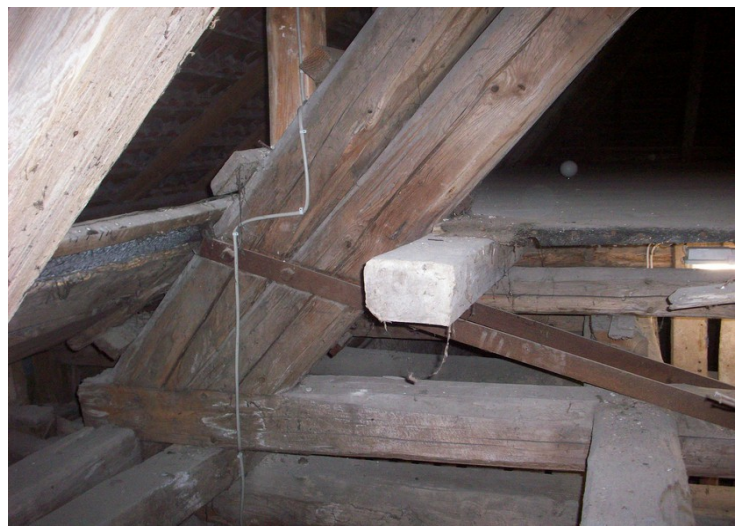

Figure 9. Photo of detail of the foot point of the Laves' balken.

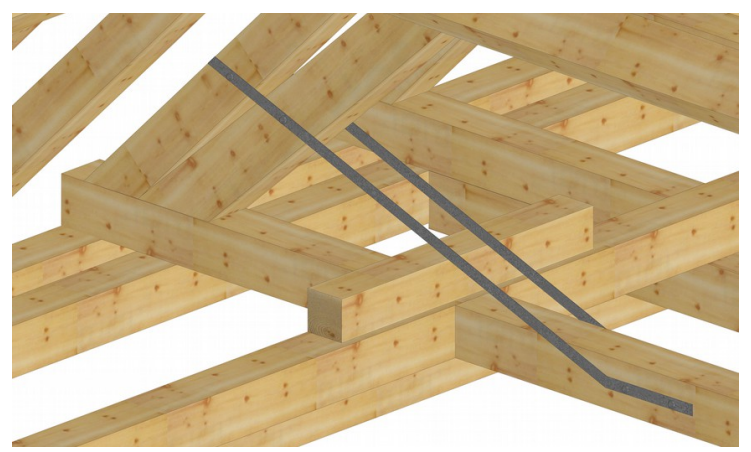

Figure 10. Photo of detail of the foot point of the Laves' balken.

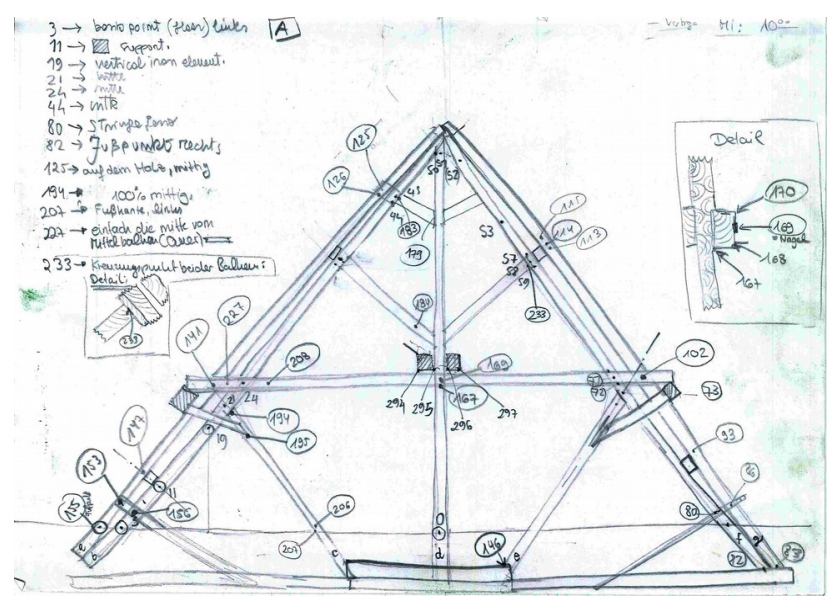

Figure 11. Hand-measured sketches the pagoda with observation on the connection's methods and fasteners.

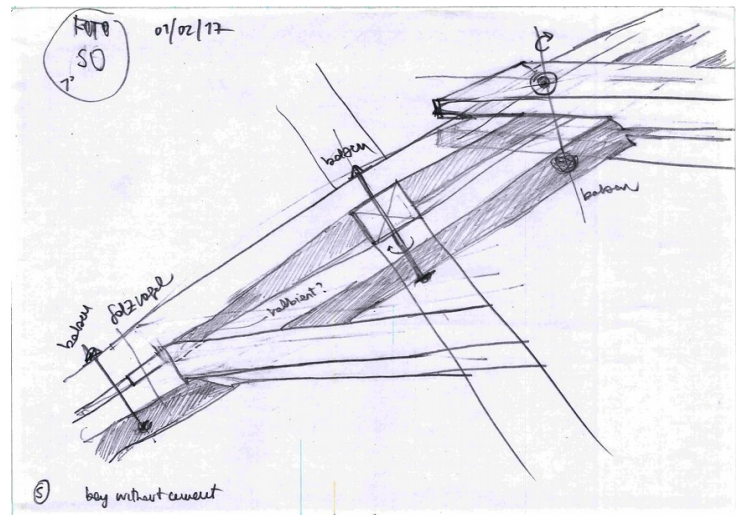

Figure 12. Measured survey on a detail of the pagoda with observation on the connection's methods and fasteners.

\section{CRITICS AND PROBLEMS TO THE AUTOMATIC SCANNING AIMED TO THE STRUCTURAL ANALYSIS}

The automatic scanning can highly improve the understanding on the object; nevertheless, to achieve the final goal of structural analysis of the building, some methodological observations have to be made about the aim and the output of the modelling. First factor, is the representation of the output model, the second observation is about the distinction between deformed and non-deformed structure, and finally, the creation of a static model that is a static system.

The process of automatic scanning to the creation of a 3D and framework model requires big efforts for the storage, management, and a tedious work for the representation of the output structure. Already the first step to generate a comprehensible measurement from the scan requires the knowledge of the role of the elements that are in the point cloud; if they have a structural or non-structural function have to be clear since the beginning. Second, the key to realistic structural modelling relies in the modelling of the connections. Taking as example the Figure 10, drawn in CAD program directly from the point cloud and photos, it represents only the external aspect of the connection, the intersection of the main rafters with the cross section of the tie beam. With the aim of modelling for the structural analysis, the foot point (as many 
other connection points in the structure) represents not only the connection as it looks like, but also a sensitive point for the next structural analysis that depends on geometric factors of the used joinery technique. Therefore, the lack of information in the survey of the structural details, also the internal fashioning of the connections that secure one structural elements to another, like dimension and shape of tenons, laps pins, bolts, etc., requires an additional photographic and direct survey (Figure 11) that implement the final output model.

More, some observations between deformed and non-deformed structure have to be done. On one side, the aim of the CAD representation is the description of the state-of-the-art of the structure. The actual status must be reproduced, as much as possible faithful to the original, including the structural deformations and missing elements. On the other side, the aim of the modelling of the framework for structural analysis is the representation of the original state (or as much as possible similar to the unknown former state) and the application of external loads on it, that justified the actual structural deformations. Here, when the geometry is automatically generated from the exact measurement, emerges a methodological problem. In fact, considering the final static model, we take over, with the model that we obtain from the scanning, the deformations from a structure that has been already loaded (for example in self-weight), and we apply stresses that already caused a part of the deformations on it. The calculation according to the second order theory (iterative that considers the application of loads on a deformed structure) has to be questioned. The correct structural analysis should be lead on a new (ideal and perfect) structure, based on the geometry of the (deformed) scanned one, consciously reproduced in a framework model loaded with self-weight and other external actions. Therefore, the scanned (deformed) structure should be considered only as reference for the development of the framework model for the structural analysis, not as final one!

The final step is the developing of a proper static system as static model. This work is even more demanding, and cannot be automatized. The first problem is the application of the stresses that one structural element or connection can bear. In fact, some timber elements or connections could be able to bear only compressive and not tensile stresses. In this case, the input on the beam's load-bearing behavior should be manually manipulated. Another problem is the hyperstatic nature of old timber frames. Many structural systems were not conceived under laws of modern science of construction, but are learn-bydoing structures. Therefore, after the calculation can possibly result that any structural element are redundant, or inconvenient, and/or the general structure is too weak. The computer could lead to contradictions with the reality. These two final problems can be only be solved through the direct knowledge of the structure by the person that will model the framework model or will conduct the structural analysis.

\section{CONCLUSIONS}

The survey of timber structures through scanner equipment is a complex topic. Some particular considerations have to be done before and during the survey on the field, in order to obtain the correct output: the CAD or the structural analysis models. The automatism of the scanning shows negative and positive aspects that have to be known, before to be handled. The main points to focus are the complexity of timber structures, the automatic meshing, and the kind of information available with a laser scanner that may be completed.
The first negative aspect is the number and complexity of timbers. To avoid becoming overawed of it, the timber frame and the associated components of the building need to be broken down into achievable and manageable tasks (BertoliniCestari, 2016). To avoid unnecessary work during the postprocessing, it is essential to reduce the amount of stations, and to choose the best position for them to collect basic pieces of information on all structural elements.

The second negative aspect is that the topological position of the points in the point cloud is unknown; therefore, there is not any $3 \mathrm{D}$ model directly available from the cloud. For this reason, the CAD model is generated manually during the postprocessing, through section, sketches or photos. The postprocessing of the date will require in many cases big efforts. Therefore, the level of accuracy for the scanning have to be carefully chosen as intermediate between the needed level of accuracy of the joints (more accurate) and the truss members (less accurate). The limitations that can appear during the inspection will eventually require a manual, more in-depth investigation for the constructional details.

On the positive side, the physical survey of timber buildings is greatly assisted if a measured survey is available.

For what concerns the CAD modelling, the great amount of information offered by the measured survey permits the representation of the complexity of the structure in a very clear and precise form. All the surplus elements and the elements of disturb can be presented or omitted, in dependence of the needs of the inspector, but always manually. The understanding of the overall roof-structure is important, and makes it easier for the surveyor to identify local alterations and any timbers that are eventually missing. The final CAD model is therefore very detailed.

The modelling with the aim of structural analysis did not follows only the point cloud offered by the laser scanning technology, but had to be integrated with the direct survey of the elements through photos and measured sketches. On one side, the main pieces of information on the structure, like the sections on two main axes, and the global shape of the pagoda are easily extrapolated thanks to the box tool in the ReCap program. On the other side, some important structural details like the joinery technique between the elements requires a survey with the background of the knowledge of the operator on similar objects or techniques.

Concluding, the surveying of a timber structure, finalized to the representation and structural analysis of it, must always include:

1. the conscious automation of the process according to the required final model;

2. the integration of the automatic survey with sketches, photos and direct survey;

3. the general knowledge on operation principles of the surveyed typology of structure.

\section{ACKNOWLEDGEMENTS}

The authors kindly acknowledge the Niedersächsisches Landesamt für Denkmalpflege (NLD) for the recommendation and the possibility to enter the interesting case study. Mr. Yahya Ghassoun of the Institute of Geodesy and Photogrammetry of Technische Universität Braunschweig is also acknowledged for the technical support. 


\section{REFERENCES}

Bertolini-Cestari C., Invernizzi S., Marzi T., Spano A. (2016) Numerical survey, analysis and assessment of past interventions on historical timber structures: the roof of Valentino Castle, Journal of Heritage Conservation. 45/2016 (doi:10.17425/WK45VALENTINO)

Cruz H., Yeomans D., Tsakanika E., Macchioni N., Jorissen A., Touza M., Mannucci M, Lourenço P. B. (2013). Guidelines for the On-Site Assessment of Historic Timber Structures, International Journal of Architectural Heritage: Conservation, Analysis, and Restoration, DOI:10.1080/15583058.2013.774070

Gemeinde Holle (a): Derneburg, Stand der Seite: 05/2016; Tag des Downloads: 14.10.2016; http://www.derneburg.de/schlossderneburg/geschichte/das-kloster

Gemeinde Holle (b): Derneburg. Schloss Derneburg, Stand der Seite: 05/2016; Tag des Downloads:14.10.2016; http://www.derneburg.de/schloss-derneburg/schloss-derneburg

Moons, T., 1997. Report on the Joint ISPRS Commission III/IV Workshop "3D Reconstruction and Modelling of Topographic Objects", Stuttgart, Germany http://www.radig.informatik.tumuenchen.de/ISPRS/WG-III4-IV2-Report.html (28 Sep. 1999).

Smith, J., 1987a. Close range photogrammetry for analyzing distressed trees. Photogrammetria, 42(1), pp. 47-56.

Smith, J., 1987b. Economic printing of color orthophotos. Report KRL-01234, Kennedy Research Laboratories, Arlington, VA, USA.

Smith, J., 1989. Space Data from Earth Sciences. Elsevier, Amsterdam, pp. 321-332.

Smith, J., 2000. Remote sensing to predict volcano outbursts. In: The International Archives of the Photogrammetry, Remote Sensing and Spatial Information Sciences, Kyoto, Japan, Vol. XXVII, Part B1, pp. 456-469Balletti C., Berto M., Gottardi C., Guerra F. (2014) 3D technologies for the digital documentation of an ancient wooden structure. International Journal of Heritage in the Digital Era 2014;3(1):9-32.

Stadtarchiv Hannover: HBS Laves Derneburg. Foto eines Entwurfs von Laves 1846; Entwurf des Turms in Derneburg mit Zinnenumlauf, Türmen und pagodenförmigen Dach. Hannover (25.10.2016).

Weber H. (1964). Georg Ludwig Friedrich Laves als Bauingenieur. Steinbock Verlag, Hannover. 